\title{
The Role of CAPM and Oil Prices to Analyze the Firm's Stock Return
}

\author{
Muqaddas Khalid ${ }^{1, *}$, Samya Tahir ${ }^{1} \&$ Mehreen Fatima $^{1}$ \\ ${ }^{1}$ Department of Management Sciences, COMSATS University Islamabad, Lahore Campus, \\ Pakistan \\ *Corresponding author: Department of Management Sciences, COMSATS University \\ Islamabad, Lahore Campus, Pakistan. E-mail: muqaddaskhalid@gmail.com
}

Received: April 13, 2019 Accepted: August 2, 2019 Published: August 15, 2019

doi: 10.5296/rae.v11i3.15278 URL: https://doi.org/10.5296/rae.v11i3.15278

\begin{abstract}
This paper attempts to analyze the applicability of CAPM and the effect of oil prices on firm's stock in case of Pakistan. To examine this research objective, we use the yearly data of 148 listed firms over the period of 2006 to 2015. We employ three different estimation techniques, panel correlated standard error estimation (PCSE), Driscoll and Kraay (DK) estimation and common correlated effects pooled (CCEP), to analyze the relationship between oil variables and firm's stock return. Moreover, we further estimate the variables by using robust estimation techniques to validate the empirical results. The estimations report the inapplicable of market premium in case of Pakistani firms. However, the oil price and lagged oil prices provides the evidence of negative and statistically significance in textile, sugar, cement, chemical and engineering sectors. On contrary, the oil prices and lagged oil prices have positive and significant impact on stock return in transportation and energy sectors. In conclusion, it is difficult to escape the conclusion that oil price has higher influence on stock returns as compared to the market premium and nearly all the manufacturing sectors are inversely affected by the oil price rise.
\end{abstract}

Keywords: Oil price, CAPM, Firm's stock return, Pakistan

JEL Classification: O13, Q43 


\section{Introduction}

The negative impact of price of oil is supported by many studies including the study of (Hamilton 1983). There are other studies to predict the crude oils volatility as mentioned in the studies of (Maclaury, 1978; Ederington and Guan, 2010; Melic and Thomas, 1997). The other school of thought depicts the raise in economic growth is a clue of the improvement and development of the stock market performance. The increase in the oil price leads to the reduction in the revenues of the companies that are having the oil as an essential factor in the production cost either indirect or direct (Waheed et al., 2017). The scenario depicts that the increment in the price of oil leads to increase in the production cost leaving minimal profit margin for the company decrease in the price of stock as well. Moreover, the inefficiency of the stock market due to the increased oil price comes with the lagged returns.

This paper studies the impact of the increase in oil price on the stock market returns. The study is inspired by the work of three pioneering research studies in the respective field (Narayan and Sharma, 2011, 2014; Chen et al., 1986; Driesprong et al., 2008; Jones and Kaul, 1996). The study of Jones and Kaul (1996) used regression model based on time series for investigating the relationship between oil price and returns of stock. The study data was divided on quarterly basis based on 4 developed countries Canada 1960-1991, UK 1962-1991, US 1947-1991 and Japan 1970-1991. The study proved that the real oil prices had a negative impact on the returns for all the countries included in the study. Chen et al. (1986) used the model of multivariate regression using the US oil prices and keeping the returns as the macroeconomic variable's function. The study data was calculated from 1953 to 1983 on the monthly basis. This study concluded the insignificant relation of oil prices on the returns. Driesprong et al. (2008) used the data of 48 developing and developed countries from 1973 to 2003 on the monthly base to investigate the impact of the oil prices on the market stock returns. The relation was found negative like the previous studies; results were significant for the 17 from 18 developed countries. The significance and negative impact also noted for the developing countries, the majority of the relationships are though empirically insignificant. The main and identical point in all these studies was the emphasis on the aggregate market. Chen et al. (1986) focused on the aggregate market of US, Jones and Kaul (1996) focused on the aggregate market of 4 developed countries including, US, Canada, UK and Japan. Third study of Driesprong et al. (2008) focused on the aggregate market of 48 countries including developing and developed countries. These all studies focused on the macro perspective to examine the impact of oil prices on market returns. However, the studies of Narayan and Sharma $(2011,2014)$ emphasized on the micro level analysis; their main motive was to examine the relationship between oil market and firms level stock returns in case of US. Narayan and Sharma $(2011,2014)$ examined the relationship between oil returns and firm's stock returns in US.

\subsection{Projected Relationship of Market Returns and Oil Prices}

This hypothesis represents the investigation regarding the different impact of oil prices on market returns of different firms. This point is considered crucial as the dependence on oil in different firms varies as per their sector. This point can be more cleared with the example that 
the dependence on the oil is less crucial in the sectors including banking, computer and real estate as compared to the sectors including transportation, electricity, manufacturing and energy where oil is considered as main component in the production.

Friedman (1977) described that the uncertainties and the volatilities caused by the increasing inflators' rates can lead to the reduction in economic growth in future. These inflated rates can be a consequence of shock from oil prices. The inflated rates affected from the increase in the oil price can consequence in a number of ways including the uncertainty regarding the oil price movements on the higher level, misrepresentations of price signals and the downfall in the efficiency of economic growth. These all can result in the negative impact of performance of stock market, leading to a negative impact of rise of oil prices on the market returns. It was argued by Black (1987) that while making an optimal investment portfolio decision there is a trade off or constraint faced by the economies in the returns and risks. The investments made by investment agents are high only in case of higher rate of return, so that potential losses can be covered in case of crisis. The other point of his argument included that there is a choice for the economies to decide between low variance with technology of low expected returns and high variance with technology of high expected returns. This depicts that high growth average countries would be having the higher variance.

Ramey and Ramey $(1991,1995)$ also presented an argument by using an equilibrium model that includes the productivity shock and oil price shocks. The model includes the findings that shock in oil price when considered as productivity shock can lead to the decrease in the output. The model argues that there is a permanent decrease in the output mean due to the output volatility at higher level. They implied the model through the example of advance investment of a firm in the technology, this cause the average output at lower level due to volatility and as a result the production level of all the firms become sub-optimal. This scenario leads to the shake in the current production levels, decrease accumulation factor and finally decrease in the economic growth. Doran and Ronn (2008) also showed a risk premium of negative status for the options data and futures of the heating oil, crude oil and natural gas for the period of 10 years. This caused the performance of stock market to be restrictive and unresponsive. According to (Hamilton, 1983), the increase in economic risk is caused by shocks in oil prices, whereas the stock market performance and higher economic growth is associated with higher level of risk. As a result, high variance leads to the better performance of the stock market. The existing studies of Jones and Kaul (1996) and Driesprong et al. (2008) concluded the negative affect on aggregate market returns due to the oils prices.

\subsection{Lagged Impact of Oil Price on the Returns of Firm}

The insulated impact of the oil price on the returns of the firm is followed by three reasons. There was an argument made by Jones and Kaul (1996) that stated the statistical significance of lagged oil price, recommends to the point that either there is an impact of oil shocks that vary the anticipated stock returns or the stock return market is not efficient. The second reason pertains to the potential hypothesis of under reaction. A batch of the work on the particular study admitted that the investors underreact to the information within the short tenure whereas in the long tenure investors overreact to the information. The models to prove 
the same hypothesis were anticipated by (Daniel et al., 1998; Barberis et al., 1998; Poteshman, 2001; Narayan and Sharma, 2011, 2014). The hypothesis assumed that the investors don't react on the new information. Time is required to take some action that is why the results appear after some time. Daniel et al. (1998), was of the view that there is overreaction of the stock market to the private information signals and under reaction to the public information signals. The oils prices are observed by investors on real time base by interpreting it as public information. Therefore, the news of oil price faces under reaction in the finance market.

Hong and Stein (1999) described a mode in which under reaction will hypothetically take place. A hypothesis consisting of steady diffusion of the information was proposed by them. A model consists of the energy traders and the news watchers was used by both of them to show when news watchers do keen observation of information they miss the prices of the other watchers and as a result leads to under reaction of the information hypothesis in short tenure. The second mode to understand under reaction hypothesis was described by Edwards (1968) through hypothesis of conservatism. In this hypothesis the investors underreact to the public information and rely on their beliefs more regarding the news. There is also a probability on behalf of the investor to consider the information as big temporary factor. As a result, they partially neglect the information in the news. The final reason of the effect of oil prices on firm's returns can be explained via hypothesis of reversion in which it is assumed that the stock returns can be predicted with lagged and insulated information. Studies of (such as, Fama and French, 1989; Breen et al., 1990) that business cycle relate to the component that is predictable. Appropriately and relevantly, question in the paper of Pesaran and Timmermann (1995) that predictability is a result of business cycle and macroeconomic shocks magnitude.

Consequently, the study conducted is composed of different organizations that relate to the segregated 8 sectors. The efforts made for the segregation of sectors was necessary as the firms were different and heterogeneous in nature and the results could vary with respect to impact of oil price on returns in different sectors. The early studies on the particular topic are referred here because they were based on the assumption of homogeneous market and firms. The impact of the oil price on aggregate index market limits the results. This assumption is very strong. The assumption discussed above is relaxed in the respective study and the impact of the oil price is studied on the firms that were belonged to the 8 sectors only.

\subsection{Objective of the Study}

The major focus in current study is at micro level analysis in case of Pakistan. To make it more precise, the study emphasized on the impact of oil prices on the market returns at firm's level. The study is the pioneer to investigate that how firm stock returns are affected by the oil price shocks, rather stock market. Moreover, in case of Pakistan, there is no literature available that examine the categorized the firms on the size basis to investigate the impact of oil price shocks. This paper attempts to analyze the response of small size firms and big size firms to the oil price shocks. For this intention there are three hypothesis assumed in this study to make the study more focused at micro level. These hypotheses $(\mathrm{H})$ are described below: 


\subsection{Hypothesis}

H1: The oil price has different impact levels on the firms based on their respective sector locations.

H2: Lagged impact of oil price exists on the firms return in case of Pakistan.

These hypotheses were tested on the 148 firms that are listed in the Karachi stock exchange. The data of the selected firms are collected over 10 years from Jan 5, 2006 to Dec 3120015 on the yearly basis. Though the data of firms, it was segregated into different sectorial levels. In the respective study it was categorized into 8 sectors.

Concisely prophesying the results, there are two new verdicts unraveled regarding the impact of oil prices on market returns. Firstly, it was concluded that the impact of the oil prices on the market returns depends on the sector it belongs to. The findings suggested that the rise in the oil prices results in the rise of the market returns of the transportation and energy sector in comparison to other 6 sectors. The other sectors experience the fall of the market return when oil price rise. This finding is in line with the results of Narayan and Sharma (2011). Secondly, it was concluded that the impact of oil price on market returns appear with a pause or lag. The finding is more consistent with a hypothesis of under reaction in which it is argued that the investment companies and stakeholders react gradually to the public general news. That is either due to the conformist approach of the investors towards the news or due to the non-reliability or impermanent status of the news in the view of investors. It is found that the impact of oil price on market returns in done on different lag levels. It is found that all the five out of eight sectors have confirmed the negative impact on market returns due to oil price rice while two of them are positive and statistically significant.

The rest of the paper is structured in the following manner. Next section is comprised of data and methodology. It will be following the discussions regarding the results. And the final section will be comprised of conclusion.

\section{Data and Methodology}

The present study collects the data of studied variables from business recorder (brecorder.com) and energy information administration (EIA) database for firm's level stock prices and oil prices, respectively. We use WTI oil price (US dollar), whereas, the stock prices are available in Pakistani rupees. For econometric analysis we convert the stock prices in US dollar by taking exchange rate. The calculation for stock and oil return is the natural logarithm of closing price at time $t$ divide by lagged price. The function of natural logarithm is to standardize the variables for precise results. We employ panel data estimation techniques to investigate the impact of oil prices on firm's level stock return; panel correlated standard error estimation (PCSE), Driscoll and Kraay (DK) estimation and common correlated effects pooled (CCEP) estimator are employed for econometric estimations. For robust analysis, we further use pooled ordinary least square (pooled OLS), fixed effect model (FEM) and random effect model (REM) to reexamine the estimated findings. The sample consists of 148 firms 
over the period of Jan 5, 2006 to Dec 312015 on the yearly basis, due to non-availability of data before 2006 for many firms; we decided to exclude the data before 2006. The models for these examinations are as follows:

$$
\begin{gathered}
S R_{i t}=\beta_{i}+\beta_{1} M P_{i t}+\varepsilon_{i t} \\
S R_{i t}=\beta_{0}+\beta_{1} M P_{i t}+\beta_{2} O P_{i t}+\varepsilon_{i t} \\
S R_{i t}=\beta_{0}+\beta_{1} M P_{t}+\beta_{2} O P_{t}+\beta_{3} O P_{t-1}+\varepsilon_{i t}
\end{gathered}
$$

Where $S R_{i t}$ is the stock return for firm $i$ at time $t, M P_{i t}$ is the market premium that has been used for Capital Asset Pricing Model (CAPM). $O P_{t}$ is the oil price for year $t$ and $O P_{t-1}$, is the oil price at lagged one. Model-1 analysis the effect of oil prices on firms stock return in the respective period, this model attempts to explore whether oil price respond to Pakistani firms return in the upcoming year. Initially, we consider the CAPM model to examine the validity in case of Pakistan. Although a large number of studied already studied this in case of Pakistan but still there is no census at all (Iqbal and Brook, 2007; Hassan and Javed, 2011; Haque and Sarwar, 2013, Sarwar et al. 2013). In further analyses, we take oil prices in the model-1 to analyze the impact of oil prices on firm's stock return. Whereas, model-3 depicts the lagged effect of oil price change on current stock return for the case of Pakistan. In addition, we categorize the firms in eight sectors (textile, sugar, cement, chemical, transportation, engineering, banking, and fuel and energy) according to SIC industries list to investigate the oil return respond in a different way across the industries sectors (Arouri, 2011; Degiannakis, Filis, \& Floros, 2013; Elyasiani, Mansur, \& Odusami, 2011; Moya-Martínez, Ferrer-Lapeña, \& Escribano-Sotos, 2014).

\section{Results and Discussion}

\subsection{Descriptive Analysis}

The descriptive for the firm stock return (SR), market premium (MP) and oil price (OP) have given in Table-1. Descriptive statistics contains number of observations for each variable, mean for stock prices, market premium and oil prices; standard deviation for SR, MP and OP, maximum and minimum value, skewness and kurtosis. Stock return have 1480 observations with mean value 0.072 and standard deviation 0.364 , while the maximum and minimum values are 2.134 and -3.208 , respectively, these descriptive results present that stock return does not contain any outlier and the variable is fit for further analysis. The market premium (MP) has 1480 observations with mean 0.043, standard deviation 0.527. The skewness and kurtosis of market premium are 0.469 and 11.696, respectively. The oil price shows the mean is 1.064 and standard deviation is 0.825 with minimum and maximum value of 1.983 and 3.130 , respectively. The descriptive analysis of all the variables reports the normal behavior of all the variables for econometric analysis. 
H1: The oil price has different impact levels on the returns of the different firms based on their respective sector.

To examine the hypothesis, we used the following approach. There was a sample of 148 companies in total, for each of the firms the static model with homogeneous slop coefficient is estimated for the data on yearly base for 10 years. Results are testified in Table 2; the major finding is consistent with the early belief and studies that oil prices affect the returns of the firms differently based on their different sectors. This affect can be noticed either by magnitude or by signs. The significance of market premium in model-1 reports the consistence of CAPM model on case of Pakistani firms which is consistent with the findings of (Iqbal and Brook, 2007; Hassan and Javed, 2011). All the three estimation techniques, PCSE, DK and CCEP, report the similar findings in for market premium.

However, this market premium becomes insignificant when being treated with oil variables. Moreover, the value of oil coefficient in model-2 is also higher than market premium which is indicating that oil has higher magnitude than market premium. More detail analysis show that DK and CCEP estimations proved that oil price in model-2 reports to be significant at $1 \%$ level in most of the industries. On contrary, PCSE confirms the significance at $5 \%$ level which suggests the oil variable proves higher significance in case of DK and CCEP analysis. The significance of oil price is parallel to the results of (Elyasiani, Mansur, and Odusami, 2011; Degiannakis, Filis, and Floros, 2013; Moya-Martínez, Ferrer-Lapeña, and Escribano-Sotos, 2014).

Turning the attention toward industry analysis, textile, sugar, cement chemical and engineering sectors have reported the negative and statistically significance of oil price in model-2, which suggests that oil price change has significant impact on current stock return. The negative relationship depicts that manufacturing industries are adversely affected by the oil price changes. The classical illustration for this negative impact is that the oil is the main complement for industries and the rise in oil price triggers the cost of product which in turn has negative impact on accounting earning and on firm stocks. The essential difference is that the transportation sector and the fuel and energy sector have significant and positive impact of oil price on firm's stock returns. This positive relation depicts that increase in oil price can boost the firms stock returns of transportation sector and oil and gas sector in Pakistan. This is by no means unique, as oil price rise the oil and gas sector will have sale their products on higher prices which lift their earning and will transmit a positive signal in the market. This affirmative trend attracts the investors to invest in oil and gas sector which boosts the stock returns. This finding is in line with (Waheed et al., 2017; Narayan and Sharma, 2011, 2014). The banking sector has confirmed the mix evidences for all the industries analysis; the results oil price is negative for PCSE estimation, positive for DK analysis and insignificant for CCEP estimation. This mix evidences across estimation techniques suggest that results of banking sector are sensitive for different testing methods. The key point to note is that there were still majority of the cases in the banking sectors that is having instances of the more insignificant then significant impact of oil prices on firm returns. The three crucial messages emerged from the analysis. Firstly, the hypothesis supported from the results that oil prices affects the stock returns based on the sectors. This proved that the impact of oil prices on the 
firm stock returns is dissimilar. Secondly the previous studies discovered the negative and significant relationship of the oil prices and returns like Jones and Kaul (1996) and Driesprong et al. (2008), and some find no significance in the relation like study of Chen et al. (1986).

Distinctively we found that the relation either positive or negative is completely dependent on the sector of the firm to which it belongs to. This also points out the sign effect of the oil price on the aggregate market were a result of the dominant sectors or factors that make up the market and deviate the results. In this study we found that the relation of oil price and the firm's stock return using regression model was misrepresented due to the generalization. It was proved in the study that the analysis of the oil price and returns on firm's level are different not only in magnitude but also in the sign approach. Thirdly it was found that the sectors like energy and transportation that are dependent on the oil experience increase in returns with the rise in oil prices.

\section{H2: Lagged impact of oil price exists on the firms return in case of Pakistan.}

Furthermore, model-3 incorporates the lagged oil price in model 2 to examine the impact of lagged oil prices on current stock returns. Table 2 reports the findings of model-3 for all the three estimation techniques, PCSE, DK and CCEP. The coefficient of market premium still provides no evidence of significance and proves the insignificance of CAPM model in Pakistan this finding is in line with (Javid, 2008; Haque and Sarwar, 2013 and Sarwar et al, 2013). Likewise, to model-2, model-3 also depicts the insignificance of market premium when it has regressed with oil variables. This finding also confirms the insignificance of CAPM for the case of Pakistan.

In the study strong evidence is found for the significant relationship of the oil price and stock returns. Precisely from the study the lagged impact on the oil prices is having three main points. Initially we found that in the five sectors of the study including textile, sugar, cement, chemical, engineering sectors have the negative and significant impact on the stock returns at one lagged prices. The lagged oil prices positively affect the transport sectors and fuel and energy sector, whereas, this impact is significant in five out of 6 estimations. In case of banking sector, only CCEP shows the significance of lagged oil price variable. On contrary, PCSE and DK estimations prove the insignificance of lagged oil prices which postulates that lagged oil prices are also not important factor to analyze the firm's sock returns. As a result, in the second hypothesis, it is concluded that the change in oil prices not only effects in the respective period but also affects the stock prices in the forthcoming periods.

\subsection{Robust Analysis}

Additionally, for confirmation of above results, we further use the robust estimation to analyses the impact of oil price. For robust estimation, we used pooled OLS, fixed effect model (FEM) and random effect model (REM) for model-1, model-2 and model-3. The results of Pooled OLS, FEM and REM are mentioned in table-3. The results of market premium still show the positive and statistical significant impact on firm's stock return in all the given industries. However, the coefficient of market premium varies across estimation 
techniques over the industries analysis; this finding validates the results of PCSE, DK and CCEP estimations. For model-2, the robust analysis reports the negative and significance impact of oil price on firm's stock return for textile, sugar, cement, chemical and engineering sectors. This positive effect also reports that oil price rise adversely affect the stock return of manufacturing sectors. The findings of transportation sector and fuel and energy sector endorse the results of PCSE, DK and CCEP estimations; the oil price coefficients of these sectors are still positive and statistically significant. On the other hand, market premium is insignificant for model-2 estimations. Diverting to investigate the lagged oil price effect on firm's stock return, the results of market premium are still insignificant for all the eight sectors. Whereas, the table-3 presents that the impact of oil price is still negative and statistically significant in case of all manufacturing sectors. Conversely, oil and gas sector and transportation sectors are positive and significant which suggests that the stock returns of these sectors gains as the oil price rises. The lagged effect of oil prices is also negative for textile, sugar, cement, chemical and engineering sector for most of the robust estimations. For transportation and fuel and energy sectors, five out of six estimations are positive and significant which suggests that these sectors also get benefits due to the rise in oil prices over the following years. At the same time, it is true to say that oil have more prominent impact on firm's stock return than market premium which also reject the applicability of CAPM in Pakistan.

\section{Conclusion}

This study attempts to investigate the multiple aspects: firstly, this examines the applicability of CAPM in case of listed firms of Pakistan: secondly, whether oil prices have significant impact on firm's level stock return in the respective period. Finally, the study explores the role of oil prices in its following period. For this purpose, we selected the data of 148 firms over the period 2006 to 2015. We employ panel correlated standard error estimation (PCSE), Driscoll and Kraay (DK) estimation and common correlated effects pooled (CCEP) estimation techniques to analyze the CAPM model and oil variables. In addition, we use robust tests to confirm the findings of PCDE, DK and CCEP. Pooled OLS, fixed effect model and random effect model is used for robust estimations.

The main econometric estimations have reported the significance of CAPM model when market premium is regressed alone on firm's return. Whereas, when we augmented the model with oil price, the market premium becomes insignificant while oil price reports significant impact on firm's stock return. The results reveal that textile, sugar, cement, chemical and engineering sectors are adversely affected by the rise in oil prices. However, transportation sector and fuel and energy sector has confirmed positive and statistically significant relationship with stock returns, proposing that the returns of these sector becomes higher as the oil price rises. The estimations further prove the significance of lagged oil price; the lagged oil price is negative and significant for textile, sugar, cement, chemical and engineering sectors. This negative relationship can be testified by the theoretical reasoning that the rise in oil prices can push the production cost of firms that increases the product 
prices. This rise in cost can decline the purchasing power of the customers that influences the firms to reduce the production operations. The reduction in production can raise the unemployment, decrease the financial earning and transmit a negative signal in the stock market. Accordingly, the investors feel hesitation to trade in these stocks which further put some pressure on these stocks and consequently that stock returns decline (Masih, Peters, and Mello, 2011). Yet the most important point to note is that transportation sector and fuel and energy sector have reported the positive and significant impact of lagged oil prices on stock returns. The essential point to note is that the robust estimations confirm inapplicability of CAPM and the significance of oil prices. This in turn means that CAPM is not applicable in case of Pakistan and oil has significant role to analyze the firm's stock return.

All things considered then we can conclude that oil prices have significant impact on firm's stock return in case of Pakistan. However, this relationship varies across industries; mostly, manufacturing firms report the oil price rise has adverse impact on firms return. However, transportation and energy sector gets higher profits from the rise in oil prices. This finding is helpful for the investors; during the rise in oil prices they should try to buy the stocks of transportation and energy sectors. On contrary, during the decline in oil prices the investors and portfolio managers should buy the stocks of manufacturing sectors, such as textile, sugar, cement, chemical and engineering sector.

\section{References}

Arouri, M. E. (2011, 7). Does crude oil move stock markets in Europe? A sector investigation. Economic Modelling, 28(4), 1716-1725. https://doi.org/10.1016/j.econmod.2011.02.039

Black, F. (1987). Business Cycles and Equilibrium. Cambridge, MA: Blackwell.

Breen, W., Glosten, L., \& Jagannathan, R. (1990). Predictable variations in stock index returns. Journal of $\quad$ Finance, $44, \quad 1177-1189$. https://doi.org/10.1111/j.1540-6261.1989.tb02649.x

Chen, N.-F., Roll, R., \& Ross, S. (1986). Economic Forces and the Stock Market. The Journal of Business, 59(3), 383-403. https://doi.org/10.1086/296344

Daniel, K., Hirshleifer, D., \& Subra, A. (1998). Investor Psychology and Security Market Under- and Overreactions. Journal of Finance, 53(6), 1839-1885. https://doi.org/10.1111/0022-1082.00077

Degiannakis, S., Filis, G., \& Floros, C. (2013, 10). Oil and stock returns: Evidence from European industrial sector indices in a time-varying environment. Journal of International Financial Markets, Institutions and Money, 26(C), 175-191. https://doi.org/10.1016/j.intfin.2013.05.007

Doran, J., \& Ronn, E. (2008). Computing the market price of volatility risk in the energy commodity markets. Journal of Banking \& Finance, 32(12), 2541-2552. https://doi.org/10.1016/j.jbankfin.2008.04.003 
Driesprong, G., Jacobsen, B., \& Maat, B. (2008). Striking oil: Another puzzle? Journal of Financial Economics, 89(2), 307-327. https://doi.org/10.1016/j.jfineco.2007.07.008

Ederington, L., \& Guan, W. (2010). Longer-term time-series volatility forecasts. Journal of Financial and Quantitative Analysis, 45(4), 1055-1076. https://doi.org/10.1017/S0022109010000372

Edwards, W. (1968). Conservatism in human information processing. In: Kleinmutz,. In Formal Representation of Human Judgment. John Wiley and.

Elyasiani, E., Mansur, I., \& Odusami, B. (2011, 9). Oil price shocks and industry stock returns. Energy Economics, 33(5), 966-974. https://doi.org/10.1016/j.eneco.2011.03.013

Fama, E., \& French, K. (1989). Business conditions and expected returns on stocks and bonds. $\begin{array}{lllll}\text { Journal of Financial } & \text { Economics, } & 25, & \text { 23 }\end{array}$ https://doi.org/10.1016/0304-405X(89)90095-0

Friedman, M. (1977). Nobel Lecture: Inflation and Unemployment. Journal of Political Economy, 85(3), 451-72. https://doi.org/10.1086/260579

Hamilton, J. D. (1983). Oil and the Macroeconomy since World War II. Journal of Political Economy, 91(2), 228-248. https://doi.org/10.1086/261140

Haque, A., \& Sarwar, S. (2013). Effect of fundamental and stock market variables on equity return in Pakistan. Science International, 981-987.

Hassan, A., \& Javed, M. T. (2011, 8 18). Size and value premium in Pakistani equity market. African Journal of Business Management, 5(16), 6747-6755.

Hong, H. (1999). A Unified Theory of Underreaction, Momentum Trading, and Overreaction in Asset Markets. Journal of Finance, 54(6), 2143-2184. https://doi.org/10.1111/0022-1082.00184

Iqbal, J., \& Brooks, R. (2007). A Test of CAPM on the Karachi Stock Exchange. International Journal of Business, 12(4), 429-444.

Javid, A. Y. (2008). Time Varying Risk Return Relationship: Evidence from Listed Pakistani Firms. European Journal of Scientific Research, 22(1), 16-39.

Jones, C. M., \& Kaul, G. (1996). Oil and the stock markets. Journal of Finance, 51(2), 463-91. https://doi.org/10.1111/j.1540-6261.1996.tb02691.x

MacLaury, B. (1978). Opec Surpluses and World Financial Stability. Journal of Financial and Quantitative Analysis, 13(04), 737-743. https://doi.org/10.2307/2330478

Masih, R., Peters, S., \& Mello, L. D. (2011). Oil price volatility and stock price fluctuations in an emerging market: Evidence from South Korea. Energy Economics, 33, 975-986. https://doi.org/10.1016/j.eneco.2011.03.015

Melick, W., \& Thomas, C. (1997). Recovering an Asset's Implied PDF from Option Prices: An Application to Crude Oil during the Gulf Crisis. Journal of Financial and 
Quantitative Analysis, 32(1), 91-115. https://doi.org/10.2307/2331318

Mork, K. (1994). Business cycles and the oil market. The Energy Journal, 15, 15-38. https://doi.org/10.5547/ISSN0195-6574-EJ-Vol15-NoSI-3

Mork, K. A. (1989, 6). Oil and Macroeconomy When Prices Go Up and Down: An Extension of Hamilton's Results. Journal of Political Economy, 97(3), 740-744. https://doi.org/10.1086/261625

Moya-Martínez, P., Ferrer-Lapeña, R., \& Escribano-Sotos, F. (2014, 2). Oil price risk in the Spanish stock market: An industry perspective. Economic Modelling, 37, 280-290. https://doi.org/10.1016/j.econmod.2013.11.014

Narayan, P. K., \& Sharma, S. S. (2011). New evidence on oil price and firm returns. Journal of Banking \& Finance, 35, 3253-3262. https://doi.org/10.1016/j.jbankfin.2011.05.010

Narayan, P. K., \& Sharma, S. S. (2014). Firm return volatility and economic gains: The role of oil prices. Economic Modelling, 38, 142-151. https://doi.org/10.1016/j.econmod.2013.12.004

Pesaran, M., \& Timmermann, A. (1995). Predictability of Stock Returns: Robustness and Economic Significance. Journal of Finance, 50(4), 1201-28. https://doi.org/10.1111/j.1540-6261.1995.tb04055.x

Poteshman, A. (2001). Underreaction, overreaction, and increasing misreaction to information in the options market. Journal of Finance, 56(3), 851-876. https://doi.org/10.1111/0022-1082.00348

Ramey, G., \& Ramey, V. (n.d.). Technology Commitment and the Cost of Economic Fluctuations. National Bureau of Economic Research, Inc, No 3755.

Sarwar, S., Hussan, W., \& Nawaz, S. M. (2014). Empirical Relation Among Fundamentals, Uncertainty and Investor Sentiments: Evidence of Karachi Stock Exchange. International Review of Management and Business Research, 2(3), 674-681.

Waheed, R., Wei, C., Sarwar, S., \& Lv, Y. (2017). Impact of oil prices on firm stock return: industry-wise analysis. Empirical Economics, 55(2), 1-16. https://doi.org/10.1007/s00181-017-1296-4

\section{Copyright Disclaimer}

Copyright for this article is retained by the author(s), with first publication rights granted to the journal.

This is an open-access article distributed under the terms and conditions of the Creative Commons Attribution license (http://creativecommons.org/licenses/by/3.0/). 